\title{
Adapting Climate Change in Agriculture: The Sustainable Way in Nepalese Context
}

Dinesh Panday

\begin{abstract}
Nepalese agriculture is still subsistence and traditional in nature, which makes it highly vulnerable to effects of climate change. The major impacts on agriculture from climate change are due to the pattern of rainfall and increased temperature. The increased temperature, in the longer term, has negative impact on crop yield through increased rate of respiration and evapo-transpiration process causing moisture deficit in the soil and plant system due to more emission of green house gases. Under changing precipitation trends, water harvesting is crucial to facilitate water availability. An integration of agriculture with forest, agro-forestry, can be effective to mobilize local capacities in relation to climate regulation. It is indeed necessary to formulate an integrated action plan for agricultural development in which adaptation strategies are embedded within the local spatial planning in consideration of economic, social and political context. The best adaptation measure to secure against climate change is to promote the principles and practices of sustainable agricultural technology among all farmers from marginalized to capitalized ones. More importantly, the promotional technologies of sustainable soil management, ecological practices of pest management, and participatory promotion of local varieties or landraces are the major adaptive mechanism to revive our agriculture from the impacts of climate change. Such practices are helpful to promote the concept of food sovereignty, which is utterly important in the developing countries like Nepal, rather than food security.
\end{abstract}

Key words: Agricultural crops, temperature, precipitation, sustainable agricultural technologies, food sovereignty, Nepal

\section{Introduction}

Small land holding farmers are a majority of the population of Nepal. In Nepal's 26.6 million population (Census 2001), almost $80 \%$ reside in rural areas, $65 \%$ are involved in agriculture contributing $33 \%$ to the Gross Domestic Product (GDP) (NARC 2010). Farmers follow traditional agricultural patterns, relying on rainwater and seasons. The climate is influenced by the Himalayan mountain range and the South Asian monsoon. The climate is characterized by four distinct seasons: pre-monsoon (March-May), monsoon (June-September), post-monsoon (October-November) and winter (December-February). The average annual rainfall is approximately $1,800 \mathrm{~mm}$ and nearly $85 \%$ of the rainfall occurs in monsoon season. Changes in local and regional temperatures, the form and amount of precipitation, rainfall patterns, soil moisture content, and sunshine and cloudiness threaten traditional agriculture. And once the climate is disturbed, the whole agriculture system is affected.

Climate change is a phenomenon due to emissions of greenhouse gases (GHG) from fuel combustion, deforestation, urbanization and industrialization (Upreti 1999) resulting variations in solar energy, temperature and precipitation. The impacts of climate change on agriculture are both direct and indirect. A rise in temperature and both temporal and spatial changes in rainfall patterns have direct impacts, while disturbances in water resources for irrigation and incidences of pests and diseases are the indirect impacts of climate change on agriculture. The annual mean temperature trend over Nepal ranged from -0.04 to $0.06^{\circ} \mathrm{C}$ in the far-western region, 0.02 to $0.04^{\circ} \mathrm{C}$ in the mid-western region, 0.02 to $0.08^{\circ} \mathrm{C}$ in the western region, -0.04 to $0.08^{\circ} \mathrm{C}$ in the central region, and -0.06 to $0.09^{\circ} \mathrm{C}$ in the eastern region during a period showing a range of variations in the temperature trend (Practical Action 2009). Nevertheless, the temperature trends on Nepal are high when compared to global average temperature rise of $0.74^{\circ} \mathrm{C}$ in the last 100 years (1906 to
2005) and $0.13^{\circ} \mathrm{C}$ per decade in the last 50 years (1956 to 2005) (IPCC 2007).

Rainfall is becoming more and more unpredictable, which has negatively affected agriculture production since the farmers are planting and harvesting crops within certain dates of the year. Erratic rainfall events (i.e., higher intensity of rains but fewer rainy days and unusual rain) with no decrease in total amount of annual precipitation have been experienced. An analysis using a Ricardian model, showing marginally increasing precipitation during summer and winter, would increase farm income in the hilly region, but reduce it in the lowland Terai region (Thapa and Joshi 2010). Such events increase the possibility of climatic extremes like irregular monsoon pattern, droughts and floods. From 1976 to 2005 the average annual precipitation trend ranged from -10 to $20 \mathrm{~mm}$ in Nepal's eastern region, -40 to $20 \mathrm{~mm}$ in the central region, -30 to $40 \mathrm{~mm}$ in the western region, -20 to $10 \mathrm{~mm}$ in the mid-western region, and -10 to $20 \mathrm{~mm}$ in the far-western region (Practical Action 2009).

Nepal's crop fields are experiencing erratic rainfall and unprecedented fog and drought, fostering the spread of pests (insects, diseases, and weeds) and hyper-pests in crops, thus threatening the food security of every region. Over the long term, the increased temperature has negative impacts on crop yield through increased rates of respiration though crops get more carbon dioxide $\left(\mathrm{CO}_{2}\right)$ gas for photosynthesis due to more emission of greenhouse gases. Increase in temperature around the crop canopy and in the soil accelerates the process of evapo-transpiration causing moisture deficit in the soil and plant system. The situation results in impaired physiological functioning of field plants, clogged soil structure, and disrupted eco-friendly microbial and macrobial activity. Intense rainfall from the poorly managed agro-ecosystem results in the loss of huge amounts of top soil (fertile soil) that has formed naturally over thousand years. By the 1970s the Green Revolution, involving the use of chemical fertilizers, chemical 
pesticides and heavy machinery, drove widespread shifts in the agricultural sector from subsistence and low external input agriculture to mono-cropping with high yielding varieties (HYVs). And, because the high yielding varieties were more susceptible to pest outbreaks, the rapid spread of Green Revolution agriculture throughout most countries of South Asia was accompanied by a rapid rise in pesticide use (Rosset, Collins and Lappe 2000). In some cases, these components have eliminated our climate adaptive local landraces, thus creating problems for food sovereignty.

Climate change, coincident with increasing demand for food, feed, fiber and fuel, has the potential to irreversibly damage the natural resource base on which agriculture depends, with significant consequences for food insecurity. Out of 26.6 million population of Nepal more than 2 million face food insecurity (IAASTD 2008). The relationship between climate change and agriculture is two-way agriculture contributes to climate change in several major ways, and climate change in general adversely affects agriculture. Given this scenario, our need is to deliver appropriate climate adaptation technology to the farming community while respecting their local, traditional, and indigenous practices in a participatory manner.

\section{Body of Review \\ Sustainable Agriculture}

Sustainable agriculture, by its very definition, reduces harm to the environment; for example, through the reduction or elimination of polluting substances such as pesticides and nitrogen fertilizers. So do water conservation practices, soil conservation practices, restoration of soil fertility, maintenance of agricultural biodiversity and biodiversity, etc. Organic agriculture, for example, uses less fossil fuel based inputs and has a better carbon footprint than standard agricultural practices. Sustainable agricultural practices include:

- Crop rotations, which mitigate weed, disease, and insect problems; increase available soil nitrogen and reduce the need for synthetic fertilizers; and in conjunction with conservation tillage practices, reduce soil erosion.

- Integrated pest management (IPM), which reduces the need for pesticides by crop rotations, scouting, timing of planting, biological pest controls.

- Management systems to improve plant health and crops' abilities to resist pests and disease.

- Soil conserving tillage.

- Water conservation and water harvesting practices.

- Planting of leguminous crops and use of organic fertilizer or compost to improve soil fertility.

A variety of resource conserving technologies and practices have been used, including integrated pest management, integrated nutrient management, conservation tillage, agro-forestry, water harvesting in dry land areas, and livestock and aquaculture integration into farming systems. These practices not only increase yields, but also reduce adverse effects on the environment and contributed to important environmental goods and services (e.g., climate change mitigation), as evidenced by increased water use efficiency and carbon sequestration, and reduced pesticide use (Pretty, Noble et al 2006). In developing countries, evidence from hundreds of grassroots development projects show that increasing agricultural productivity with agro-ecological practices not only increases food supplies, but also increases incomes, thus reducing poverty, increasing food access, reducing malnutrition, and improving the livelihoods of the poor (Pretty 1995). More importantly, the promotional technologies of sustainable soil management, ecological practices of pest management, and participatory promotion of local varieties or landraces are the major adaptive mechanism to revive our Nepalese agriculture from the impacts of climate change.

\section{Sustainable Soil Management Approach}

Climate change adaptation for agricultural cropping systems requires a higher resilience against both excess of water (due to high intensity rainfall) and lack of water (due to extended drought periods). A key element to respond to both problems is soil organic matter, which improves and stabilizes the soil structure. Increase in vigorous growth of food crops due to more availability of $\mathrm{CO}_{2}$ may reduce the nutrients available in soil. Increase in temperature may lead to reduce the level of soil organic carbon, soil micronutrients and enhance decomposition by activating the microbial population in the soil (Malla 2003). Increased soil respiration with global warming is likely to provide a positive feedback to the greenhouse effect (Raich and Schlesinger 1992). Agricultural sectors: mainly crops, livestock's and horticulture largely depend on the given water sources in the country. Variability in climate and weather is major reason for change in moisture availability in the soil. The rapid evapo-transpiration due to increase in temperature, will demand more water to reduce drought. Water availability governs the physiological active period and crop production. Rain water harvesting techniques is the most scientific and cost effective way of recharging the ground water and reviving the water table for agricultural operations.

The U.N. Food and Agriculture Organization (FAO) promotes conservation agriculture (CA) as a best practice in which minimal soil disturbance (no-till, NT) and permanent soil cover (mulch) combined with rotations, promote a more sustainable cultivation system for the future. Sustainable agriculture technology revives soil productivity and fertility through the promotion of sustainable soil management practices like management of farmyard manure and animal urine, mixed cropping, mulching, green manuring, promoting diversity in the field, promoting use of organic manure with local materials, contouring, managing run off, promoting minimum tillage practice, using light farm equipments, and identifying and upscaling local technologies. These practices are more responsible to manage plant-soil-water relationships to make the soil physical, chemical, and biological properties suitable for crop production.

\section{Eco-friendly Pest Management Approach}

Increase in temperature and $\mathrm{CO}_{2}$ will lead to an increase in population of pests and severity of diseases in presence of host plant. An increase in insect population leads to demand for more use of pesticide, which 
unknowingly causes considerable harm to ecosystem as well as human society. The situation is intense due to the use of heavy doses of chemical pesticides that destroy faunal diversity in agro-ecosystem. It has also changed the micro-environment of the crop field resulting in the development of hyper pests and these hyper pests further account heavy crop loss. Pesticides can be replaced by integrated pest management (IPM) techniques including avoidance of monocultures and improvements in soil quality. The practices include promotion of animal urine, plant extracts, farm diversification, maintenance of beneficial insects, microbes, invertebrates, and microvertebrates, use of local botanical pesticides, promotion of local pest resistant varieties, participatory selection of crop varieties, etc. Nepal government has launched IPM as a national program. These technologies could help minimize projected pest losses and thereby help maintain crop yields.

\section{Participatory Variety Development Approach with Focus on Local Landraces}

Farmers traditionally use diverse crops, trees and wild plant species, livestock and aquatic species to sustain and enhance their livelihoods. Due to the extension of modern agriculture, most of our local landrace species are disappearing and are in the verge of extinction as they are replaced by high yielding hybrid ones. In the context of changed climate, the hybrid varieties are more susceptible to climate extremities such as flood, drought, high temperature, cold, fog, and pests. It has been observed that local varieties that suffer from climate variability can re-colonize their populations simply by seed/planting materials flow that takes place in farmer to farmer networks. Traditional knowledge/practices and local genetic resources play key roles in farmers' and community's capacities to adapt to climate change. Farmer's ability to cope with the impact of climate change will be strengthened if research and development institutions build upon the traditional knowledge and practices of farmer seed and germplasm management systems.

Farmer seed system allows the dynamic change that characterized crop landrace systems-open, decentralized genetic systems that are constantly evolving to fit farmer's needs and environmental changes-could help in coping with the uncertainty generated by climate change in agriculture (Bellon 2010). Seed banks promote conservation and use of local genetic resources, while providing access to seeds among poor and marginal farmers after crop failure and during seed shortages, thus reducing vulnerability to crop loss. Farmers of Lekhnath village of Kaski District, Nepal, were managing more than 60 local landrace species of important crops and medicinal plants for their livelihood. Community-based biodiversity management as a methodology to realize in situ/on-farm conservation through strengthening farmer seed systems, and promoting climate resilient integrated home garden production systems, where scientific inputs from scientists and indigenous inputs from local community are merged in the process. Although indigenous knowledge is not based on scientific facts, they are formulated on the basis of past observations and experiences and have proven to be closely matched with scientific reality as indigenous measures do enable adaptation to harsh environment in many cases (Shrestha 2011). Tharu farmers in the lowland plains of Nepal are replacing rice crops with sugarcane and lentil to cope with uncertain rainfall (Maharjan, Sigdel et al 2011). Rather than promoting food security, such practices are helpful in promoting the concept of food sovereignty, which is important in developing countries like Nepal.

\section{Conclusion}

Climate change is real and underway, so there is a need to identify and adopt methods to cope with vulnerabilities in the agricultural sector. Climate change represents a major threat to agro-biodiversity. However, agricultural biodiversity should be a key component of climate change adaptation strategies. Increases in temperature and $\mathrm{CO}_{2}$ levels are also threatening to bring out the hidden-hunger problem in humans by lowering the essential nutrient contents of food crops. Food sovereignty seeks to return control over all aspects of agricultural biodiversity to local food providers, building on their knowledge and skills to develop localized, bio-diverse food production systems. Sustainable agriculture can contribute significantly to increased food production, as well as make a significant impact on rural people's welfare and livelihoods. A thriving and sustainable agricultural sector requires both integrated action by farmers and communities, and by policy makers and planners to search out and deliver measures adaptive to the changed climate.

Dinesh Panday, B. Sc. Ag: Agriculture Graduate (Soil Science) in 2011 from Institute of Agriculture and Animal Science, Tribhuvan University, Nepal. Mr. Panday won as Young Agricultural Scientist (2010 Nepal first place, 2011 Nepal second place and 2012 India Subcontinent Zone second place with 250 USD) which was awarded by Alltech Young Scientist Program, USA and country coordinator of 350.org team, a United States nonprofit public charity working on climate change. Before this, he has published two articles on Journal of India Agronomy 2010 and Journal of Central Department of Botany, ICBLCC 2010. He is working as Program Coordinator in Agriculture Awareness on Sustainable Development (AASD NEPAL) and now he is involved as admin of http://agriculturenepal.com (social platform for Nepalese agriculturists).

Corresponding address: relorteddinesh@gmail.com

\section{References}

Bellon, M., 2010, 'Do we need crop landraces for the future? Realizing the global option value of in situ conservation', in A. Kontoleon, U. Pascual and M. Smale (eds.), Agrobiodiversity and Economic Development, New York: Routledge.

IAASTD, 2008, International Assessment of Agricultural Knowledge, Science and Technology for Development; URL: www.agassessment.org.

IPCC, 2007, Climate Change 2007: Climate Change Impacts, Adaptation and Vulnerability: Summary for Policy Makers, a report of Working Group II of the Intergovernmental Panel on Climate Change, Fourth Assessment Report, Geneva: IPCC Secretariat/World 
Meteorological Organization; URL: http://www.ipcc. ch/publications_and_data/ar4/wg2/en/contents. html.

Maharjan, S.K., E.R. Sigdel, B.R. Staphit and B.R. Regmi, 2011, 'Tharu community's perception on climate changes and their adaptive initiations to withstand its impacts in Western Terai of Nepal', International NGO Journal 6(2):035-042.

Malla, G., 2003, 'Impact of climate change on water and soil health', Agriculture and EnvironmenT (Nepal Ministry of Agriculture and Cooperatives), pp.63-71.

NARC, 2010, NARC's Strategic Vision for Agricultural Research (2011-2030), Kathmandu: Nepal Agricultural Research Center.

Practical Action, 2009, Climate Change and Adaptation in Nepal. a Field Report submitted by Small Earth Nepal (SEN) to Practical Action Nepal Office, Kathmandu.

Pretty, J., 1995, Regenerating Agriculture Polices and Practies for Sustainability and Self-reliance. Pp 336. London: Earthscan.

Pretty, J.N., Noble, A.D., Bossio, D., Dixon, J., Hine, R.E., Penning de Vries, F.W.T. and J.I.L. Morison, 2006, 'Resource-conserving agriculture increases yields in developing countries', Environmental Science and Technology (Policy Analysis) 40(4):1114-1119.
Raich, J.W. and W.H. Schlesinger, 1992, 'The global carbon dioxide flux in soil respiration and its relationship to vegetation and climate', Tellus $B$ 44:81-99; URL: http://onlinelibrary.wiley.com/ doi/10.1034/j.1600-0889.1992.t01-1-00001.x/ abstract; doi: 10.1034/j.1600-0889.1992.to1-100001.x.

Rosset, P., Collins, J. and F.M. Lappe, 2000, 'Lessons from the Green Revolution: Do we need new technology to end hunger?', Tikkun Magazine 15(2).

Shrestha, A.M, 2011, 'Preparing for climate change: integrating local inputs for prioritizing adaptation measures in Nepal', a paper presented at the Colorado Conference on Earth System Governance: Crossing Boundaries and Building Bridges, USA; URL: cc2011. earthsystemgovernance.org/pdf/2011Colora_0160. pdf.

Thapa, S. and G.R. Joshi, 2010, 'A Ricardian analysis of the climate change impact on Nepalese agriculture', MPRA Paper No.29785 (Munich Personal RePEc Archive); URL: http://mpra.ub.uni-muenchen.de/29785/.

Upreti, D.C., 1999, 'Rising Atmospheric CO and crop response', SASCOM Scientific Report, pp.1-8.
...Continued from Page 72

B.P. Tripathi, Ph.D. (Soil Science) and Senior Associate Scientist at the International Rice Research Institute (IRRI)-Nepal Country Office in the Nepal Agricultural Research Council (NARC), Kathmandu.

Corresponding address: b.tripathi@irri.org

R.K. Mahato, M.Sc. (Plant Breeding) and Senior Scientist (S4) at the Nepal Agricultural Research Council (NARC), Kathmandu.

R.B. Yadaw, M.Sc. (Plant Breeding) and Senior Scientist (S3) at the Nepal Agricultural Research Council (NARC), Kathmandu.

S.N. Sah, M.Sc. (Plant Breeding) and Senior Scientist (S4) at the Nepal Agricultural Research Council (NARC), Kathmandu.

B.B. Adhikari, M.Sc. (Agronomy) and Lecturer at the Institute of Agriculture and Animal Sciences (IAAS), Lamjung Campus, Nepal.

\section{References}

Adhya, T.K., 2010, 'Climate change and rice production in India: Research and future strategies', a paper presented at the International Conference on Climate Change and Rice in the Unfavorable Environments, in Siem Reap, Thailand, May 4, 2010.

Barclay, A. 2009, 'Scuba rice: Stemming the tide in floodprone South Asia', Rice Today 8(2): 26-31 (published by the International Rice Research Institute, Philippines).

Bauman, B. and M. Aureus, 2009, 'Every drop counts', Rice Today 8(3):16-17.
Choudhary, D.K., B.P. Mahato, L.L. Shrestha, G. Thakur, D. Ghale, and K.H. Ghimire, 2004, 'Rice varietal improvement for rainfed lowland areas in subtropical regions of Nepal', in Rice Research in Nepal, Proceedings of the 24th Summer Crop Workshop, Kathmandu: National Rice Research Programme (NRRP) and Nepal Agricultural Research Council (NARC).

Haefele S.M. and R.J. Hijmans, 2007, 'Soil quality in ricebased rainfed lowlands of Asia: Characterization and distribution', pp. 297-308 in P.K. Aggarwal PK, J.K. Ladha, R.K. Singh, C. Devakumar and B. Hardy B (eds.), Science, Technology, and Trade of Peace and Prosperity, Proceedings of the 26th International Rice Research Conference, 9-12 October 2006, New Delhi, India (co-sponsored by the International Rice Research Institute, Philippines and India, the Indian Council of Agricultural Research, and the Indian National Academy of Agricultural Sciences).

MOAC, 2000/01, Statistical Information on Nepalese Agriculture, Kathmandu: Ministry of Agriculture and Cooperatives/Agri-Business Promotion and Statistics Division.

MOAC, 2009, Statistical Information on Nepalese Agriculture, Kathmandu: Ministry of Agriculture and Cooperatives/Agri-Business Promotion and Statistics Division.

Pandey, S., 2011, 'Changing the face of rice', Rice Today 10(2):11-12.

Reyes, L.C., 2009, 'Making rice less thirsty', Rice Today 8(3):12-15. 